\title{
Earnings and Employment Dynamics for Africans in Post-apartheid South Africa: A Panel Study of KwaZulu-Natal ${ }^{1}$
}

\author{
Paul L. Cichello ${ }^{\mathrm{a}}$, Gary S. Fields ${ }^{\mathrm{b}}$, Murray Leibbrandt ${ }^{\mathrm{c}}$

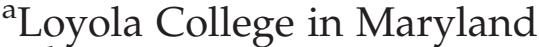 \\ ${ }^{\mathrm{b}}$ Cornell University and \\ ${ }^{\mathrm{c}}$ University of Cape Town
}

The labour market is central in determining individual and household wellbeing in South Africa. Therefore, an understanding of earnings and employment dynamics is a key policy issue. However, the absence of panel data has constrained empirical work addressing these issues. This paper makes use of a regional panel data set for KwaZulu-Natal to begin the study of earnings and employment dynamics. The authors find that, on average, working-aged Africans in KwaZulu-Natal experienced large gains in earnings during the period 1993-8. These gains were progressive in nature, with the highest quintile of 1993 earners and those originally employed in the formal sector actually experiencing zero or negative growth in their average earnings. The average gain in earnings varied substantially depending on the employment transitions experienced by labour force participants. Obtaining formal sector employment is found to be an important pathway to growth in earnings, yet not exclusively so. The majority of those who get ahead do so by retaining employment in a given sector or moving into the informal sector. The dynamism of the informal sector over this period is shown to be an important contributor to the progressive growth in earnings. Government policies that seek to increase employment and earnings in the informal as well as formal sectors are recommended. Understanding the constraints preventing the vast number

${ }^{1}$ We gratefully acknowledge thoughtful comments on earlier versions of this paper from conference participants at the 2000 Trade and Industrial Policy Secretariat Conference, the 2002 Annual Development Policy Research Unit Conference, and also from participants in seminars held in the Economics Departments of the University of Cape Town and the University of Natal. Special thanks are owing to Geeta Kingdon, Jeremy Seekings and our reviewers. This work was supported by a grant from U.S. Agency for International Development via Robert Nathan Associates. 
of unemployed from engaging in informal employment is shown to be a key issue for future work.

\section{Introduction}

The problems of low labour market earnings and high unemployment are at the forefront of debates about labour market policy in contemporary South Africa. High and rising unemployment rates contribute massively to poverty, but many people also earn little in the labour market because they work for few hours per week or receive low hourly wages, particularly in the informal sector. For individual South Africans, moving between the categories of unemployment, informal sector work and formal employment usually means big shifts in earnings and well-being. To understand poverty and inequality in South Africa, it is therefore crucially important to examine earnings dynamics and the patterns and dynamics of shifts (or transitions) between the categories of involvement in the labour market.

The orthodox view of contemporary labour market dynamics in South Africa points to very low entrance rates into regular employment (i.e., the opportunities to move into formal sector employment are small in comparison with the number of people wanting to make this move). Recent studies confirm this by showing that while there was growth in formal sector employment in the late 1990s, this was far short of the number of jobs required to match new entrants (Poswell, 2002; Statistics South Africa, 2002).

On the earnings side, real wages in regular employment have stayed constant or increased despite the fall in employment (Fields et al., 2000; Fedderke and Mariotti 2002). Wage trends thus appear to be insensitive to unemployment. It has been argued that this wage rigidity, due primarily to labour market legislation, contributes to the inability of the labour market to create formal sector jobs and to a lack of integration of earnings and conditions of employment between the formal and informal sectors of the economy (Nattrass, 2000a).

Most recent analyses of these employment and earnings issues have carried out econometric modelling using national data from surveys such as the 1993 survey conducted by the South African Labour and Development Research Unit (SALDRU) at 
the University of Cape Town or the 1995 October Household Survey conducted by Statistics South Africa. Data from these surveys provide 'snapshot' views of the operation of the labour market at one point in time. Using these data, studies have revealed the importance of a range of factors, including race, gender, education and location, in the determination of both employment and earnings (Fallon and Lucas, 1998; Hofmeyr, 2000; Bhorat and Leibbrandt, 2001; Kingdon and Knight, 2000b, 2001a). In addition to these factors, hours of work, public/private divisions, industry, occupation, union membership, and racial and gender discrimination have also been shown to be significant determinants of earnings (Moll, 1993; Mwabu and Schultz, 1996, 1998, 2000; Jensen, 1999).

Given the static nature of these data, the authors have been appropriately reluctant to make simple extrapolations from their analyses of the labour market at one point in time to dynamic earnings and employment issues. A number of empirical studies have attempted to deal with these dynamic questions by comparing data from at least two cross-sectional surveys. These studies have shown that one can use these series of cross-sections to profile accurately employment, unemployment and earnings changes at aggregate and even disaggregated levels. The analysis of aggregate, sectoral and occupational employment trends has highlighted the impacts of trade and technology in driving formal sector employment changes (Bhorat and Hodge, 1999; Edwards, 2000). The analysis of unemployment has shown that both measured unemployment rates and the profile of the unemployed are robust across data sets and across time (Klasen and Woolard, 1999; Nattrass, 2000b; Kingdon and Knight 2001a). The analysis of earnings has revealed a persistence of large earnings inequalities (Bhorat, 2000a,b; Moll, 2000), large average earnings differences by race and gender that cannot be accounted for by measurable characteristics of the earners (Moll, 2000; Allanson et al., 2002; Rospabe, 2001) and large average wage premia for unionised African workers (Hofmeyr and Lucas, 2001; Rospabe, 2001; Michaud and Vencatachellum, 2001).

This use of a series of cross-sectional surveys has added to our understanding of the evolving nature of the labour market over the 1990s. However, there are inherent difficulties associated with using a series of cross-sections to explore labour market dynamics. If the data sets tell similar stories over time, as is the case with 
the unemployment studies, there is no way of knowing whether this is because the labour market has operated in a stable fashion between the surveys or whether there have been changes in earnings and employment for certain individuals and groups but these changes have netted out to similar aggregate snapshots. Generally, repeated cross-sections cannot deal with the movement of people between labour market segments, or between jobs within sectors or with related real earnings changes over time. This is a particular concern if policy makers are really interested in knowing which specific individuals or groups are experiencing movement in the labour market and, in particular, who are the winners and losers from the current operation of the labour market.

To study these important dynamic issues more thoroughly, we need the kind of longitudinal data from panel studies that has not been available until very recently. In this paper we use the panel data from the KwaZulu-Natal Income Dynamics Study (KIDS). KIDS provides data on a panel of African and Indian households in urban and rural parts of the province of KwaZulu-Natal, with surveys conducted in 1993 (as part of the countrywide SALDRU survey) and again in 1998. The panel data set, described in detail by May et al. (2000), contains information on workers, their earnings, the sector of the economy in which they work and many more features of the households in which they live.

Most previous work using the KIDS data has focused on household-level issues (Maluccio et al., 2000; Carter and May, 2001; Leibbrandt and Woolard, 2001; Fields et al., 2003a,b). We will discuss some additional details of these mobility results in the conclusion to the paper. For now, the key point to note is that in each paper the labour market plays a key role in determining household mobility patterns. For example, Fields et al. (2003b) find that changes in the labour market status of the household head is the most important factor driving changes in real household incomes. Leibbrandt and Woolard (2001) find that the addition or loss of a job is the major factor moving a household out of or into poverty.

Thus, this household literature prompts a detailed interrogation of labour market dynamics. That said, excluding other work by the authors, only a few studies to date have used the KIDS data to deal with earnings and employment mobility at the individual level (Keswell 2000, 2002; Dinkelman 2002). Keswell (2000) constructed mobility matrices for terciles (i.e., thirds) and quintiles (fifths) of 
the earnings distribution and estimated equations exploring the key determinants of transitions between various labour market states. A key finding of his study is that individuals and households in the bottom and top groups of the income distribution exhibit much less mobility (as gauged by change in tercile or quintile) than those in the middle. Keswell (2002) supports this contention and goes on to argue that it is this uneven mobility pattern that undergirds increased inequality within the panel between 1993 and 1998. Dinkelman (2002) uses the panel to ascertain whether those searching for employment in 1993 have a higher probability of being in employment in 1998 than those who said that they wanted a job but were not searching in 1993. She finds that the searching unemployed are more likely to be employed in 1998. Her multivariate analysis indicates that household and community effects are more important in driving success in finding employment than demographic variables such as education, age and location.

In this paper, we use the KIDS panel data to answer three questions about the earnings change experienced by African labour force participants in post-apartheid KwaZulu-Natal. First, how did earnings change for African labour force participants as a whole? Secondly, how did initially low-earning African labour force participants fare in absolute terms and relative to those who were initially high earners? Thirdly, to what extent is the progress made by labour force participants driven by transitions between employment and unemployment, or between informal sector and formal sector employment, and to what extent is progress driven by other factors?

We reach the following major findings. First, African labour force participants in KwaZulu-Natal experienced large gains on average, although there is large variation around this average. Secondly, low initial earners had large average gains, faring better than those who started with high initial earnings. Thirdly, transitions between employment and unemployment and between formal and informal employment have a strong impact on real earnings, but these real earnings changes are not always as we might expect. In particular, movements from formal to informal employment are frequently accompanied by real earnings gains. Additionally, the sizeable earnings changes that take place for those who do not experience a change in sector implies that dynamics within sectors also deserve attention. Demographic variables - in particular, education and gender-are found to make surprisingly little difference. 


\section{Data and Methodological Choices}

The data used in this analysis come from the KIDS, January 2003 re-release. ${ }^{2}$ The survey probability weights were corrected to incorporate the loss of households that accompanied the re-release. All statistical analysis incorporates these weights and standard errors are corrected to account for clusters.

Labour market analysis is conducted on a sample of 1,079 individuals who were 25- to 54-year-old residents of KIDS panel households in 1993 and were again resident in 1998. ${ }^{3}$ The age restriction is designed to capture changes in labour market outcomes for people who were actively engaged in the labour force throughout the period 1993-8. In essence, we seek to define a set of dynamic labour force participants, excluding those in the process of entering or exiting the labour force for demographic reasons. ${ }^{4}$ Fifteen per cent of sample individuals in the 25- to 54-yearold age range reported being unavailable for work in both 1993 and 1998 and were also excluded from analysis. An individual is deemed unavailable if he/she (i) reported not working and (ii) gave as the reason for not working something other than having searched but could not find work or there were no jobs available.

This definition of a dynamic labour force participant is quite inclusive. Kingdon and Knight (2000a) provide compelling evidence that workers who are discouraged, i.e., those who report they were not employed because no jobs were available, should be considered full members of the labour force. Using this broad definition of unemployment, cross-sectional surveys place the unemployment rate in South Africa in the 31-9\% range in the late 1990s (Kingdon and Knight, 2000b). Our definition actually goes one step further by including as dynamic labour force participants

${ }^{2}$ Carter et al. (2003) provide more details on this re-release. In short, it was discovered that some household information in the original release was fabricated by survey personnel. After an extensive verification process (which included visits to over half of the clusters in the survey), six clusters were removed from the original KIDS release because the data appear to be fabricated.

${ }^{3}$ This analysis uses a de facto definition for resident household members. To qualify, a person must have resided in the household for at least 15 days in the month before the household was surveyed.

4 There is a literature detailing the difficulty that many new entrants into the labour market have had in gaining employment in South Africa (see, e.g., Bhorat and Leibbrandt in Bhorat et al., 2001). Thus, there is a possibility that the inclusion of those younger than 25 in 1993 would have swelled the ranks of those who were not employed in either of 1993 and 1998. 
those who reported being unavailable in one period, but actively engaged in the labour force as employed or unemployed workers in the other. In our sample of panel individuals, the unemployment rate for African dynamic labour force participants is 45\% in 1993 and $43 \%$ in 1998.

By including only single-period non-participants, the paper cannot provide a complete analysis of non-participation or a balanced comparison between a non-participant group and an unemployed group. These are important topics but they are not the focus of this paper. Indeed, for the purposes of the paper, two people who move, respectively, from unemployment and nonparticipation in 1993 to employment in 1998 are both treated as nonemployed, zero-earners in 1993 and employed earners in $1998 .^{5}$

Among those who are employed, workers are characterised as formal or informal. A worker is said to be a 'formal sector worker' if he/she was employed in a wage job that was expected to last indefinitely or if he/she was a professional self-employed person. On the other hand, a worker is said to be an 'informal sector worker' if he/she was in casual wage employment (a wage job that is of limited or uncertain duration), in non-professional self-employment or in domestic service. ${ }^{6}$ In this study, a person's work status is classified as either non-employed, informally employed or formally employed.

All earnings and earnings change data are in terms of real monthly earnings using 1993 rand as the numeraire. ${ }^{7}$ In addition to cash payments, earnings include food, housing and transportation subsidies that are paid by the employer. The earnings for

5 As a sensitivity check on the results derived under this definition, the authors redid much of the analysis in this paper under an alternative definition of the dynamic labour force that excludes those who were labeled as a non-participant in either period. Key results of this paper, such as the positive average change in earnings, the progressive nature of changes with respect to initial earnings and the average earnings changes based on initial and final work status, are shown to be robust to this specification. Results and analysis, including a more detailed rationale for the inclusion of those who are labeled as a non-participant in one period, are available from the authors upon request.

6 This definition of formal and informal employment differs from the definition in the October Household Survey and some literature in South Africa where formality is defined based on the VAT status of the employer.

7 The 1998 earnings data were deflated by 1.410. This was based on the national CPI index for September 1993 and March 1998. These two months contained the interview date of the median household. There was relatively little inflation in the period of interviewing in both years. 
self-employed persons require more assumptions. First, the survey actually provides information on net profits from self employment. This clearly embodies both the return to labour and the return to capital associated with this activity, and is not strictly identical to the wage payments of formal sector worker. However, the capital stock is of limited value for most businesses and the authors believe this approximation is quite good. ${ }^{8}$ Secondly, these figures suffer from the fact that 1998 figures are based on net profits earned in the previous month rather than average monthly profits. 9 Agricultural home production could not be broken out on an individual level and is thus excluded from the personal earnings measure. For the most part, this does not seem to be a major loss as such home production is best thought of as supplementing labour earnings rather than substituting for other labour earnings. ${ }^{10}$ Earnings from wage work in the agricultural sector are included.

Given that the survey was conducted in August to November in 1993 and from March to June in 1998, seasonal influences may impact estimates to some degree. However, this seems unlikely to account for the changes detailed in this paper. First, as previously mentioned, the earnings from home agricultural production are extremely limited in South Africa. Secondly, for seasonal factors to explain the substantial gains in earnings, the months of the 1993 survey (August to November) would have to be times of extreme

${ }^{8}$ Data on the value of capital stock owned by businesses are provided by the survey. The average real value of capital among the informal workers was R1,968 and R1,039 in 1993 and 1998, respectively. These averages were driven primarily by a few cases and fall to R281 and R347, respectively, when the top five values are removed. Tables 2, 3 and 5 were recreated after netting out returns to capital assuming a 5\% annual rate of return. Results are available from the authors upon request. There were very limited changes to these tables. For example, the average change in earnings for those who were in the informal economy in 1993 falls by less than 6 rand. The only large change resulting from these assumptions is noted in the discussion of Table 3.

9 Self-employment profits were computed on a per business basis and were given to those working in the business in a somewhat arbitrary manner. If two persons worked in the business, the profits were split 2:1 in favour of the one listed as most active in the business. Similarly if three persons were in the business, profits were split 4:2:1, with the owner (listed in 1998 only) getting the largest portion regardless of time spent. Two alternative split rules, one splitting profits evenly across individuals and the other having a more extreme split (4:1 for two person splits and 7:2:1 for three person splits), were also analysed. These alternative rules had little effect on the primary results/conclusions of this paper.

10 This fact, unusual for Africa, is well documented. See, e.g., Carter and May (1998). 
income deprivation and the months of the 1998 survey (March to June) would have to be months of surplus income. A look at how Statistics South Africa seasonally adjusts GDP and earnings data suggests that this is not a reasonable seasonality pattern in South Africa. ${ }^{11}$ Thus, the effects of seasonal earnings flows do not appear to explain our results.

The last note that we make concerning our earnings variable is that it undoubtedly contains some measurement error. In assessing how this will impact our results, we first need to define the properties of such measurement error. We will follow a standard depiction of such measurement error, assuming that it is an additive, mean zero error term, independent of all observable characteristics and independent across time. In this case, our reported average change in earnings for the panel as a whole or by initial characteristics, other than initial earnings, should still be accurate reflections of the true underlying relationship.

The intuitive problem with comparing reported earnings change to initial earnings is that the reported change in earnings has, as one of its components, the same realisation of measurement error that was found in the initial reported earnings. This can lead to a spurious negative correlation and cause us to overstate the extent to which the initially poor get ahead relative to the initially non-poor. ${ }^{12}$ One way to get around this is to compare reported change in earnings to an estimated initial earnings variable which has been cleansed of measurement error. In earlier work, the authors have used this approach and found the progressive nature of earnings changes discussed below to be robust to these concerns (Cichello et al., 2001b). ${ }^{13}$

Such an estimation approach to rid the influence of measurement error is not feasible in the multivariate section of this paper. In this case, estimation via an instrumental variables approach requires a variable that effectively predicts initial earnings yet is uncorrelated to earnings change except through the correlation with initial earnings. We were not able to find such a variable.

11 For example, in 1998 the GDP series for total value added (excl. agriculture) quarterly adjustments were $(+2.2 \% \mathrm{Q} 1 ;+1.2 \% \mathrm{Q} 2 ;-0.9 \% \mathrm{Q} 3 ;-2.4 \% \mathrm{Q} 4)$. These minor adjustments suggest production is higher later in a given year. Wage data seasonal adjustments also suggest higher earnings at the end of the year. These minor adjustments cut across a broad spectrum of industries.

12 A more technical discussion can be found in Fields et al. (2003).

13 This analysis was completed on data from the original release of the KIDS data. 


\section{Did African Workers Get Ahead or Fall Behind in}

\section{KwaZulu-Natal?}

Panel individuals gained an average of R136 over the four and a half year period. Given that the average earnings among panel members was R367 in 1993, this is equivalent to an increase in average earnings of $7.1 \%$ per annum. This level of earnings growth is surprisingly high, particularly given that the annual GDP growth rate in South Africa in this time period was approximately $2.7 \% .{ }^{14}$ There are a variety of reasons why the two rates could be so disparate. First, analysis in this study looks only at earned income, rather than all components of GDP. Secondly, the study is not for the entire South African population, but is restricted to prime-aged African workers in KwaZulu-Natal. Still, the strength of these gains was surprising to the authors. In order to ensure that this result is not driven by changes of just a few individuals or a large erroneous response, we also recalculated the growth rates excluding the top and bottom $1 \%$ of earnings changes. In this case, the average earnings gain was R109, or $6.2 \%$ per annum. Thus, the conclusion that panel participants enjoyed a sizeable average gain in earnings is robust to concerns that it is driven by just a few individuals in the sample.

As we are analysing longitudinal data, this increase in average earnings does not necessarily imply that people have higher expected lifetime earnings. If workers are simply moving along a fixed upward sloping age-earnings profile, we would still typically expect average earnings to increase over the five-year period. In previous work, however, the authors demonstrate that these average earnings gains go beyond the increases typically associated with aging four and a half years in the KwaZulu-Natal labour market (Cichello et al., 2003). In that study, the authors show that average earnings for a given age tend to be higher in 1998 than 1993 among panel participants. Simulations of the estimated average increase in earnings expected due to aging in the sample population explain less than half of the increase found, even under the most generous assumptions. Other simulations suggest a negligible effect on average earnings from the aging of the sample population. Thus, the authors conclude that the aging of the sample population is not driving the increase in average earnings.

14 Source: Statistics South Africa; average quarterly GDP (annualised) 1993:4-1998:2 (available at http:/ / www.statssa.gov.za). 
Despite these large average gains, an alarming $30 \%$ of the panel population were dual zero earners, having no change in earnings, chiefly because they were not working in either period. ${ }^{15}$ Still, considerably more people were getting ahead than falling behind, with $40 \%$ experiencing positive gains and 30\% experiencing declines.

Figure 1 presents a kernel density function of the earnings changes, excluding the previously mentioned dual zero earners. The $x$-axis is normalised, with each unit representing R560, the low earnings line. ${ }^{16}$ It is clear that many individuals have experienced earnings changes of a sizeable magnitude. Even if dual zero earners are included, fully $40 \%$ of panel participants reported positive or negative changes with magnitudes greater than half of the low earnings line (R 280).

The prevalence of large earnings changes was not driven solely by people moving into and out of unemployment. Large changes in earnings were also quite common among those who were working in both periods. Figure 2 presents a kernel density function of earnings changes first for those individuals working in both periods and secondly for those individuals employed in 1993 or 1998 (but not both). The right side of the checkered line, therefore, predominantly represents those who were unemployed in 1993 but employed in 1998, while the left hand side of this line similarly represents those who moved from employment in 1993 to unemployment in 1998. Earnings changes for those employed in both periods include earnings changes for people moving between formal and informal sectors, as well as for people who remained in a given sector. On the whole, the diagrams are similar, suggesting that employment in both periods does not necessarily imply a small earnings change experience. ${ }^{17}$ Further details on how the changes in

${ }^{15}$ Zero earnings (i.e., zero profits) were reported from about a dozen informal workers in each year.

${ }^{16}$ Bhorat and Leibbrandt in Bhorat et al. (2001) calculate that for 1995, given average rates of employment and unemployment within households and given the value of the household poverty line for a household of average size and composition, each employed member is required to earn R650 per month to bring that household's income to the poverty line. We followed this precedent and defined the 1993 equivalent, R560, as our low earnings line.

17 The authors do not claim that these distributions are identical. Indeed a Kolmogorov-Smirnov test rejects the null of identical distributions at the $95 \%$ confidence level. The change in earnings may be smaller for those employed in both periods, but many will be surprised at their size relative to those entering or exiting employment. 


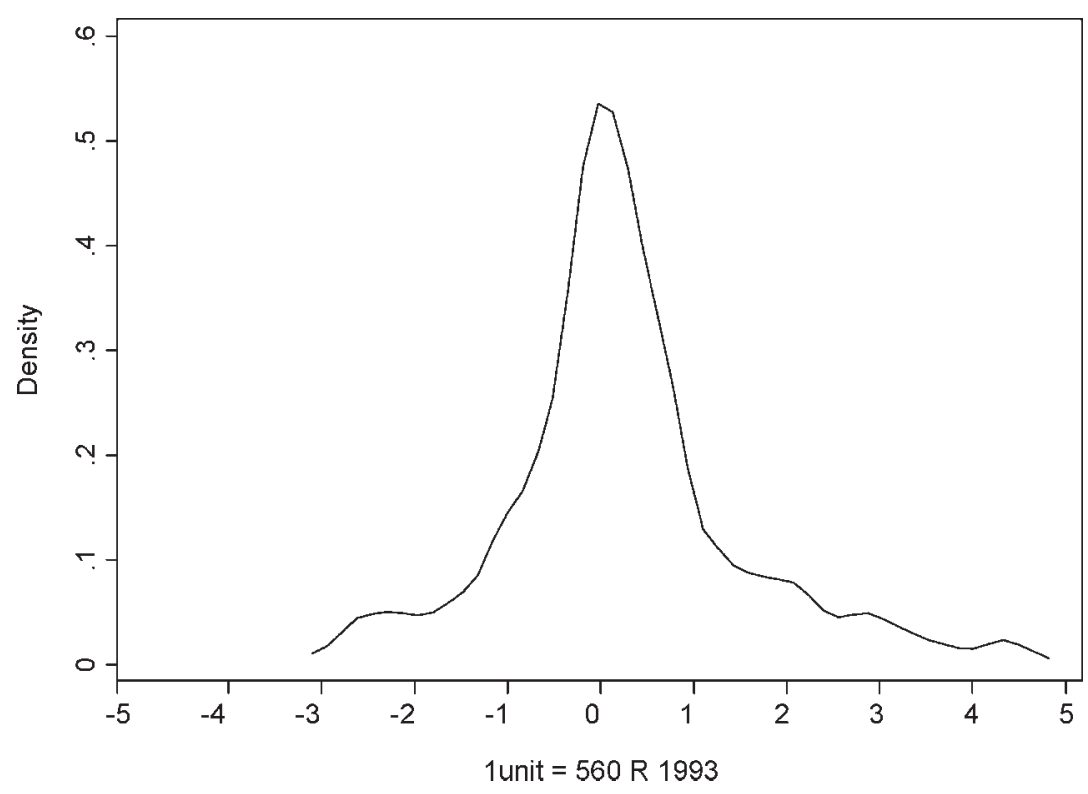

Figure 1: Earnings Changes Among Panel Persons, Excluding Dual Non-Employed. Source: KwaZulu-Natal Income Dynamics Study (KIDS)

earnings are related to specific work status transitions will follow in the latter part of this paper.

These results from this section present a fairly optimistic picture of the earnings changes experienced by the African labour force in KwaZulu-Natal since the end of apartheid. Despite the large pockets of stagnation and the fact that many individuals are experiencing large negative changes, the average change in earnings for prime-aged workers is large and positive and there are more positive than negative changes.

However, it is important that we not be interpreted as saying that all or even most participants are well-off in 1998. Up to this point we have only assessed average earnings changes. To assess the experience of those at the bottom end of the earnings distribution, Table 1 shows the transition experience by low earnings status across the two periods. A first look at the table is disturbing as it reveals that $62 \%$ of workers were in low earnings status in both 1993 and 1998. This large figure is heavily linked to the mass (30\%) of dual zero earners, but still shows that a considerable number of individuals are engaged in low-paying work. 


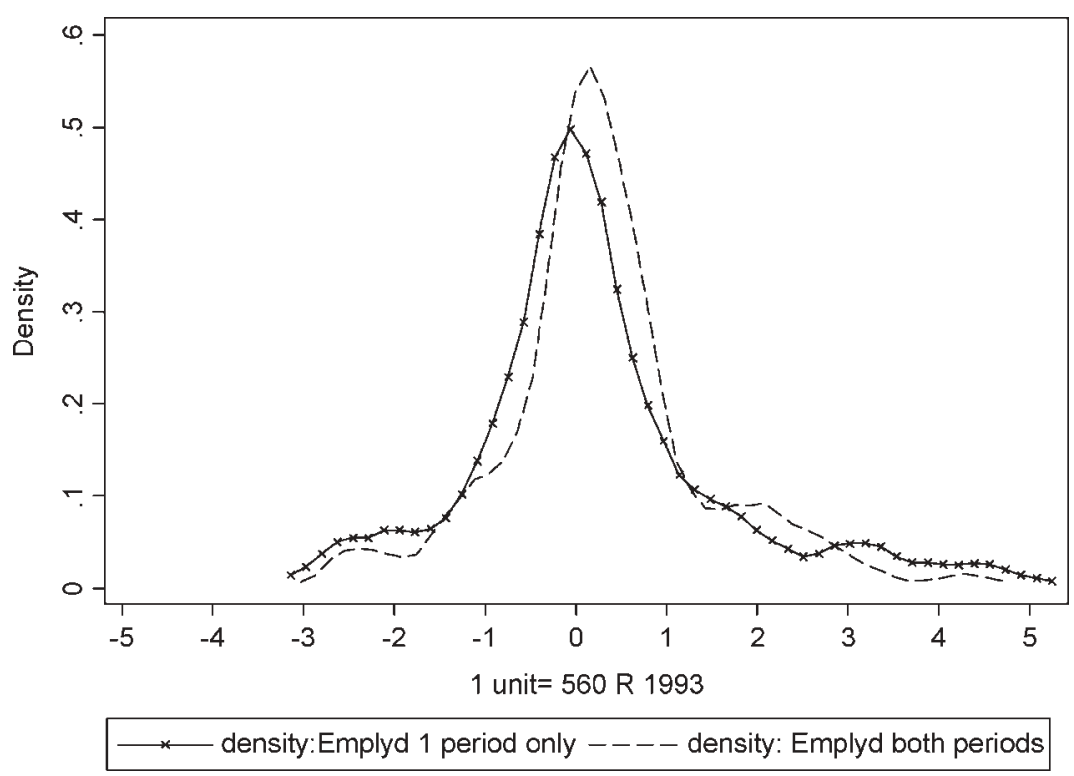

Figure 2: Earnings Changes Among Panel Persons, by Number of Periods Employed. Source: KwaZulu-Natal Income Dynamics Study (KIDS).

Table 1: Low Earner Transition Matrix: Number and Percent of Individual with Earnings Above and Below the Low Earnings Line in 1993 and 1998

\begin{tabular}{|c|c|c|c|c|c|c|}
\hline & \multicolumn{2}{|c|}{$\begin{array}{l}\text { Below low } \\
\text { earnings } \\
\text { line in } 1993\end{array}$} & \multicolumn{2}{|c|}{$\begin{array}{l}\text { Above low } \\
\text { earnings } \\
\text { line in } 1993\end{array}$} & \multicolumn{2}{|c|}{ Total } \\
\hline & $\mathrm{N}$ & $\%$ & $\mathrm{~N}$ & $\%$ & $\mathrm{~N}$ & $\%$ \\
\hline Below low earnings line in 1998 & 549 & 62.2 & $77^{\mathrm{a}}$ & 8.7 & 626 & 70.9 \\
\hline Above low earnings line in 1998 & $129^{\mathrm{b}}$ & 14.6 & 128 & 14.5 & 257 & 29.1 \\
\hline Total & 678 & 76.8 & 205 & 23.2 & 883 & 100 \\
\hline
\end{tabular}

Source: KwaZulu-Natal Income Dynamics Study (KIDS).

Low earnings line $=$ R560 (1993R).

a Risk rate: $37.6 \%$.

${ }^{\mathrm{b}}$ Escape rate: $19.0 \%$. 
Additionally, those initially earning above the low earnings line appear quite vulnerable to dropping below the low earnings line. In our data, 38\% of those initially above the low earnings line in 1993 fell below it in 1998. On the other hand, low earnings in one period does not indicate a lifetime of low earnings. Approximately one out of every five (19\%) individuals who were low earners in 1993 were able to escape this status in 1998 . If the $38 \%$ risk rate and the $19 \%$ escape rate were to persist, the steady-state outcome would be a labour force with just $34 \%$ of the population earning above the low earnings line in any given period. The vulnerability of those above the low earnings line may, therefore, become a prominent issue for labour economists.

These cautionary remarks are important and we return to them in the conclusion. That said, our overall assessment of the table is that it shows considerable gains for workers on the whole during this period. The percentage of workers earning below the low earnings level decreased by 5.9 percentage points between 1993 and 1998 . While this $19 \%$ escape rate is not as large as the $38 \%$ risk rate, it resulted in many more individuals moving above the low earnings threshold in the current period. Some of the apparent fluidity across the low earnings threshold is undoubtedly a statistical artifact driven by measurement error. However, classical measurement error alone would not explain the increase in the percentage of the overall population earning more than the low earnings threshold.

Thus, while a third wave of the panel would be extremely useful to see if those who get out of low earnings status can stay out and to see if the risk rate is reduced, the changes in the 1993-8 period were very positive in reducing the number of individuals earning minimal levels. The percentage of the dynamic labour force earnings above the low earnings line increased by $25 \%$.

\section{Were the Earnings Changes Progressive or Regressive?}

We now turn to a different issue: namely, how did the earnings change experience of those who were in the bottom sections of the earnings distribution in 1993 fare relative to those who were in the upper sections of the distribution in 1993? We find that earnings changes were progressive in that they favoured those who were at the bottom end of the 1993 earnings distribution relative to those who were at the top end of the 1993 earnings distribution. Given this 
surprising finding, we go on to use the 1993 and 1998 data as two cross-sections in order to see whether the cross-sectional perspective also supports the finding of the progressive earnings changes.

\subsection{Panel Results}

Figure 3 presents the average change in real reported earnings by initial earnings category. The results are striking in their progressive nature. Of course, the initially non-employed had to have had positive earnings gains. Nonetheless, the magnitude of the average change ( $R$ 282) is quite large. Additionally, initial low but non-zero earners showed marked progress, while initial high earners either stagnated or fell in terms of earnings. Those with the highest initial earnings experienced substantial losses in real reported earnings. Not surprisingly, a simple regression of change in earnings on initial earnings shows a statistically significant negative coefficient implying convergence towards the grand mean $(-0.43)$.

Changes by initial work status appear to confirm the progressive nature of changes reported by initial earnings category (see Figures 4 and 5). Average earnings changes are estimated to be negative among those initially employed in the formal sector. On the other hand, those initially in the informal sector experience average gains of R216 (R 146 excluding outliers). Given that average earnings was R904 among 1993 formal sector workers and R281 among 1993 informal sector workers, the estimated growth rate in earnings is $-2.6 \%$ for those originally in the formal sector and $13.2 \%$ for those originally in the informal sector. This evidence also helps to alleviate some of the concerns that measurement error might be driving the progressive relationship found in analysis based on initial earnings levels. ${ }^{18}$ Cichello (2002) also demonstrates that the positive growth in earnings and the progressive nature of these changes based on initial earnings are extremely robust to attrition concerns. ${ }^{19}$

18 The sector of employment is strongly correlated to initial earnings but does not include the measurement error term associated with the reported initial earnings. Therefore, the relationship between earnings change and sector of employment does not include the negative spurious correlation induced by measurement error when comparing reported earnings change to reported initial earnings.

19 This analysis was completed on the data from the October 2001 re-release of KIDS. It showed the above conclusions to be robust to a variety of assumptions concerning the expected earnings levels of attritors. Earnings of attritors were allowed to fall between the 25th percentile of earnings for their observable peers 


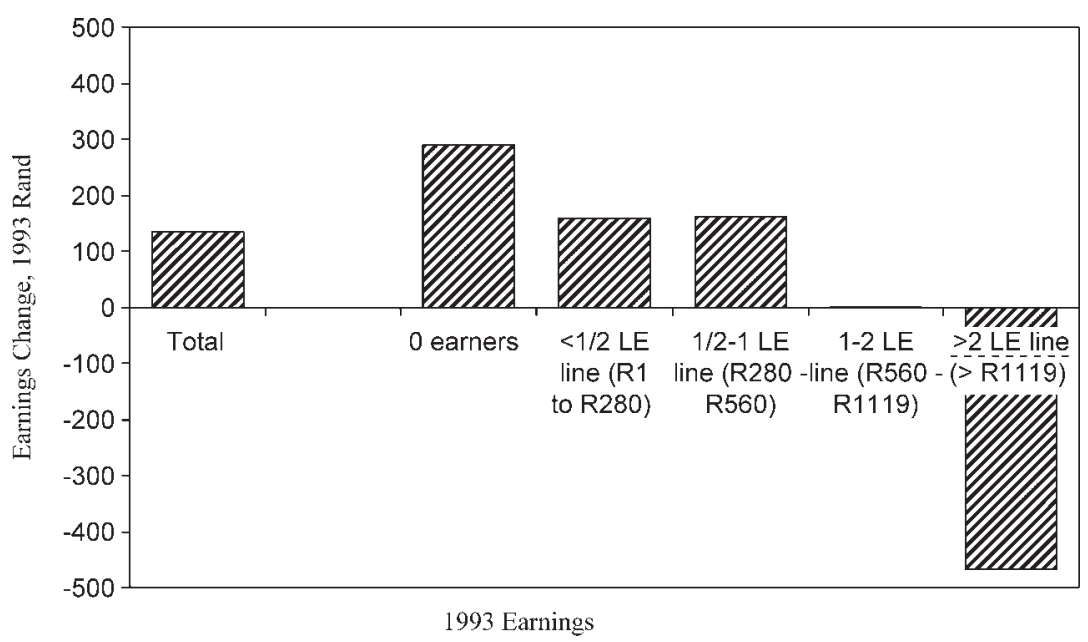

Figure 3: Average Change in Earnings Among African Dynamic Labour Force Participants in KwaZulu-Natal by Initial Position, 1993-1998. Source: Kwazulu-Natal Income Dynamics Study (KIDS).

\subsection{What if the panel approach had not been used?}

In the results presented above, progress has been measured using the second period earnings minus the same individual's first period earnings. We also assessed how individuals progressed based on specific initial household characteristics that may change over time, such as their initial earnings or work status. This can only be done with panel data. Had we not had a panel or had we chosen not to use the panel feature of the data, a different methodology would have been used. We would have taken the average earnings in the first period for a group of individuals with a given characteristic and compared this with the average earnings from the set of individuals who had that same characteristic in the second period.

Thus, with panel data, we compare how a person is doing today with how that same person was doing before. With cross-sectional data, we compare how groups of people are doing compared with each other at a point in time and then compare how this changes over time. These groups could be high earners versus low earners,

to the 75th percentile of earnings for their observable peers. In no case, were the conclusions above altered. 


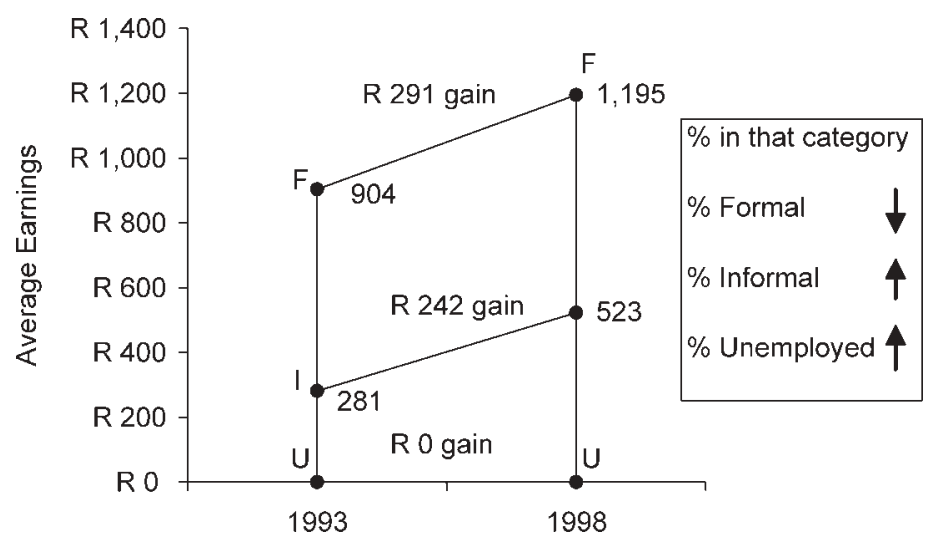

Figure 4: Average Earnings in 1993 and 1998, by Sector (Treated as Two Cross-sections). Source: KwaZulu-Natal Income Dynamics Study (KIDS).

formal workers versus informal workers, or other such comparisons. If people did not swap positions, then these two approaches would both be addressing the same question. It is important to recognise that answers in the cross-sectional setting may offer little guidance to the answers in the longitudinal setting.

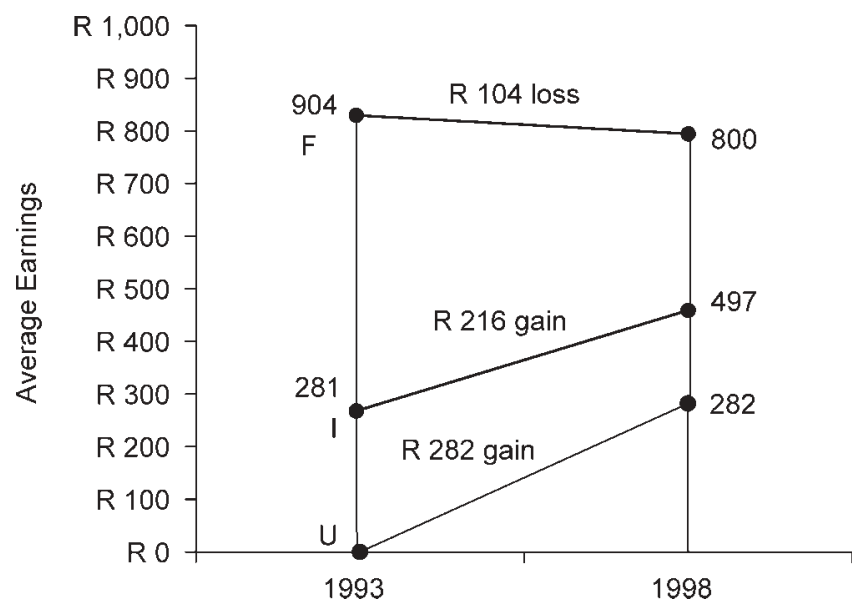

Figure 5: Average Earnings in 1993 and 1998, by 1993 Sector (Treated as Panel). Source: KwaZulu-Natal Income Dynamics Study (KIDS). 
As we shall now show, this is not only true in theory, but also in practice.

In the case of the progressive nature of changes in individual earnings in KwaZulu-Natal, the answers using the 1993 and 1998 data as two cross-sections prove to be strikingly different. First, the Gini coefficient, a commonly used indicator of inequality, rose from 0.737 in 1993 to 0.739 in 1998. This implies increased inequality of real earnings. Additionally, among workers, the percentage of persons employed in the relatively low paying informal sector increased from 36.7 to $42.7 \%$. This cross-sectional picture is in accord with other studies of earnings inequality in the South African labour market (e.g., Moll, 2000), as well as the orthodox view on the labour market that was spelled out in the introduction to this paper. It also resonates with the pre-existing literature that employment of highly skilled workers in South Africa has been increasing while that of less-skilled workers has been decreasing (Edwards, 2000; Whiteford and Van Seventer, 2000). These crosssectional facts seem to imply that cumulative advantage (the idea that the rich capitalise on connections and other benefits from their early advantage to gain even greater economic advantage) and labour market twist (the belief that the world labour market has had an increased demand for high skilled workers and decreased demand for low skill workers) had been the dominant forces.

The differences between the cross-sectional and panel results are seen clearly by comparing Figures 4 and 5 . Figure 5 shows the previously discussed progressive average change in earnings, based on initial work status. Figure 4 shows the average monthly earnings among workers in different employment sectors in 1993 and 1998. The average monthly earnings among formal workers was R904 in 1993 and R1,195 in 1998, a gain of R291. The average monthly earnings among informal workers was R281 in 1993 and R523 in 1998 , a gain of R242. The average earnings of unemployed workers was, of course, zero rand in both periods, implying no gain or loss. The cross-sectional patterns show earnings gains of similar magnitudes in the formal and the informal sectors and, of course, no earnings gain among those not employed.

Table 2 starts a more detailed, cross-sectional interrogation of the changes in the earnings from formal employment. It shows that the average earnings for those working in formal employment in 1998 were $32 \%$ greater than the average earnings for those engaged in 
Table 2: Sector Earnings Comparisons, 1993 and 1998

\begin{tabular}{|c|c|c|c|c|c|c|}
\hline & \multicolumn{2}{|l|}{1993} & \multicolumn{2}{|l|}{1998} & \multicolumn{2}{|l|}{ 1993-1998 } \\
\hline & Earnings & SE & Earnings & SE & Change in average earnings & Percentage increase \\
\hline \multicolumn{7}{|l|}{ Formal sector } \\
\hline 50th percentile & 741.7 & 34.3 & 969.3 & 48.7 & 227.6 & 31 \\
\hline 75th percentile & $1,218.7$ & 69.7 & $1,658.3$ & 101.4 & 439.6 & 36 \\
\hline \multicolumn{7}{|l|}{ Informal sector } \\
\hline Average & 281.0 & 61.6 & 523.0 & 64.2 & 242.0 & 86 \\
\hline 25th percentile & 57.0 & 8.8 & 113.5 & 16.0 & 56.5 & 99 \\
\hline
\end{tabular}

Source: KwaZulu-Natal Income Dynamics Study (KIDS). 
formal employment in 1993. The earnings level at the 75th percentile of the formal sector earnings distribution in a given year grew substantially more in percentage as well as in absolute terms than the earnings level at the 25th percentile of the earnings distribution. Figure 6 overlays the cumulative density functions for the 1993 and 1998 formal sector earnings distributions. This figure shows that earnings among the lower earners in formal employment (up to roughly the 30th percentile) were similar in the two years. On the other hand, earnings were much higher in 1998 than in 1993 for those in the higher percentiles of their respective formal sector distributions, as denoted by the horizontal gap in the two cumulative density functions.

Using this information alone, one might be tempted to conclude that things were getting better for the initially most advantaged. However, this would disregard several facts: the reduction of formal sector employment, the fact that individuals move between formal and informal or unemployed positions and the fact that individuals who were formal in both periods often trade places within the earnings distribution. Analysis of longitudinal data at the start of this section shows that earnings did not improve for the initially most advantaged.

Moreover, there is much less support for cumulative advantage from a closer cross-sectional examination of earnings from informal employment. The average earnings derived from informal employment in 1998 was R242 larger than the comparable average earnings in 1993. While this gain was a similar level of magnitude as the R291 increase in average formal employment earnings, it implied a stunning $86 \%$ increase in average informal employment earnings in just four and a half years. This large increase in average earnings occurred at a time when $24 \%$ more panel persons were engaged in informal employment compared with 1993. ${ }^{20}$ Additionally, changes in earnings were greater in percentage terms (though not in absolute terms) at the 25th percentile of the respective earnings distributions $(99 \%)$ than they were across the 50 th percentile $(76 \%)$ or 75 th

${ }^{20}$ In South Africa, such extremely large increases in the number of informal workers have been a standard finding in multiple nationally representative surveys throughout the late 1990s (see, e.g., Devey et al., 2002; Muller, 2003). These studies have been plagued with changing definitions of 'informal worker' both within and across surveys. However, the KIDS data use identical wording on the 1993 and 1998 questionnaires to help guide survey teams. Thus, this growth is felt to accurately reflect changes in the economy of KwaZulu-Natal. 


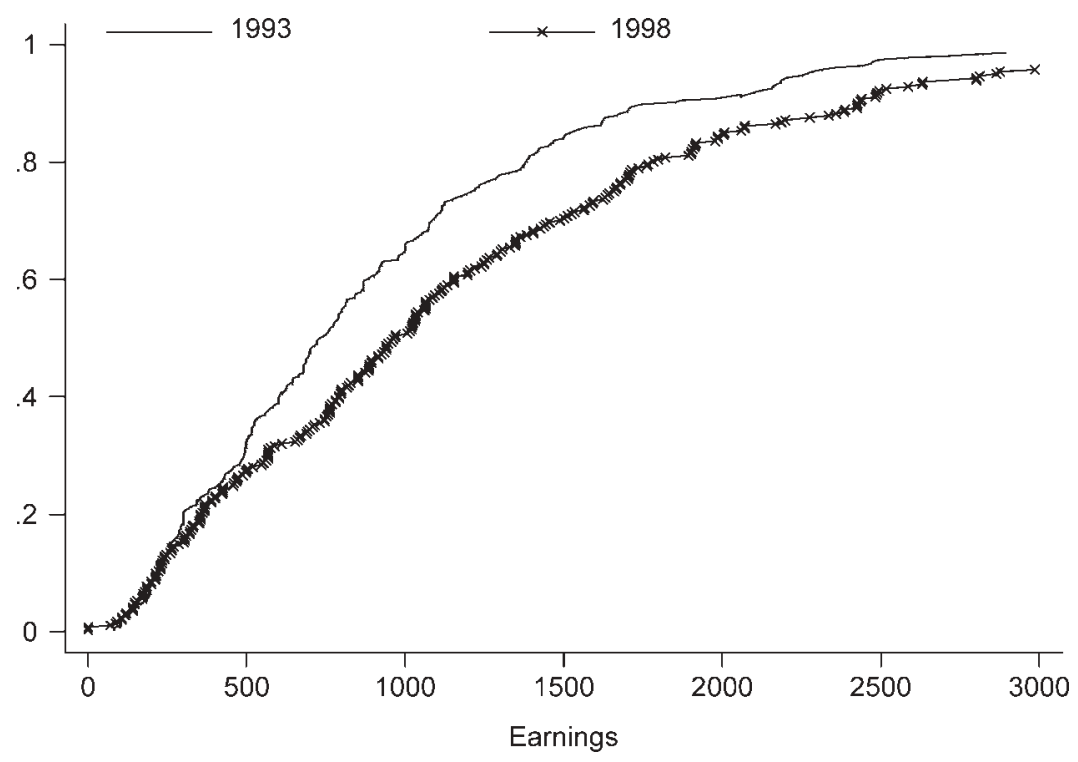

Figure 6: Earnings in the Formal Sector, 1993 and 1998 Cumulative Density Functions. Source: KwaZulu-Natal Income Dynamics Study (KIDS)

percentile (89\%). Figure 7 shows that gains across percentiles of the distribution were realised at lower percentiles in the informal sector as compared with the formal sector and that these gains were already quite substantial in comparison with the initial level of earnings.

This pattern of changes in the employment and earnings levels of those working in the informal sector in 1993 and 1998 suggests that the informal sector could have played an important role in the progressive nature of changes. The informal sector is often thought of as a middle ground between unemployment and formal sector employment. An increased number of individuals employed in this sector in 1998, therefore, is seen to imply gains for those moving from the unemployed and, typically, losses for those moving from the formal sector. Increased average earnings within the sector implies further progressivity (assuming this change is uncorrelated to initial sector of employment) as it implies lower losses for those coming from the formal sector and greater gains for those coming from unemployment or who were in the informal sector. 


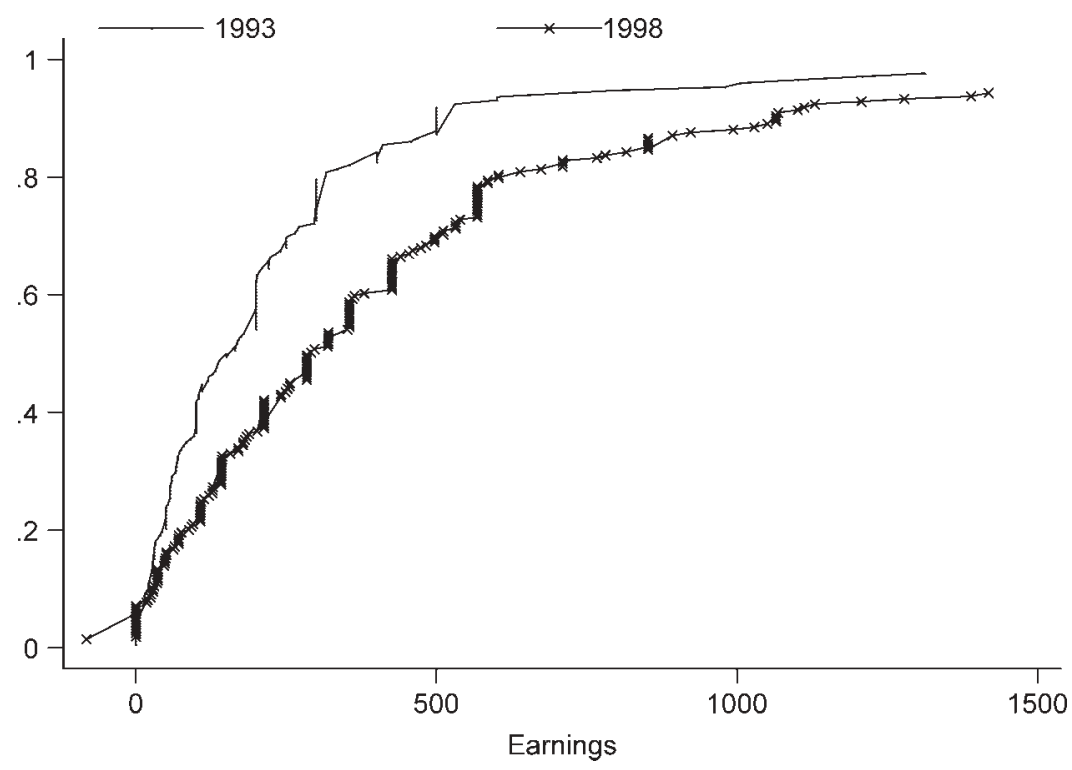

Figure 7: Earnings in the Informal Sector, 1993 and 1998 Cumulative Density Functions. Source: KwaZulu-Natal Income Dynamics Study (KIDS)

Additionally, although the informal sector is thought of as a 'middle' ground, the 1993 average earnings of informal workers were actually well below the 1993 average earnings of all dynamic labour force participants. Thus, changes for those who remain in the informal sector (if they had comparable initial earnings) would be movements starting below and moving towards the grand mean.

The changes in average earnings in the informal sector suggest that the large average gains in earnings are partially due to the increased activity in the informal market. The informal sector's contribution to total earnings among Africans moved from $15 \%$ in 1993 to $25 \%$ in 1998. The gain in the informal sector wage bill accounted for approximately one-half of the overall increase to the total wage bill. This may somewhat overstate the extent to which the informal sector drove the growth in average earnings as some of the informal employment likely was replacing what was previously formal sector employment and earnings. However, the data are highly suggestive that the informal workers were seizing new earnings opportunities that did not exist in 1993. The strength of 
these gains strongly contributed to the positive growth story that emerges.

The increased earnings at all levels of the distribution of informal sector earnings, particularly in the lower end of the distribution, are also important to note because they only further add to the quandary of why more of the unemployed do not enter the informal sector. $^{21}$ A recent article by Kingdon and Knight (2001b) concludes that either the jobs left available in the informal sector are of such low pay that there really is little 'choice' or there are restrictions to entering this sector which implies that the informal sector is not a 'free entry' sector. The substantial inflow into informal employment among panel households suggests either that some restrictions are being removed or that the potential gains are now large enough so that workers evade the restrictions that remain or risk the punishments for violating the restrictions. This is not to imply that these restrictions are easily overcome and no longer a concern. On the contrary, the opportunities in the informal sector appear more bountiful than ever and yet we still observe $43 \%$ of the population in unemployment. The quandary remains as large as ever.

In an attempt to shed some light on this issue, Table 3 further details the change in earnings for individuals who self-categorised themselves into different occupational positions. These categorical breakouts should be viewed with some reservation for two main reasons. First, the sample size is quite small for some occupational categories. Secondly, the codes are segmented into self-employed occupations and casual employee occupations when in fact the distinction between being a casual employee and a self-employed worker can be quite fuzzy, both to the respondent and to the researcher.

Despite the aforementioned reservations, Table 3 clearly demonstrates that the changes in the wages in the informal economy have occurred in a very broad manner. ${ }^{22}$ The table shows mean

21 The earnings at percentiles as low as the 10th and 15th percentiles of earnings are higher in 1998 than in 1993. As we are dealing with many small businesses, where failure rates are high, this disparity in earnings across years is gone in the lowest percentiles (by the 5th percentile of earnings). Barring a tremendous increase in the probability of businesses failing, the increased earnings at any percentile above the 10th percentile suggests that real expected profits for potential businesses are above the minimum level that people required to enter the informal sector in 1993. There appear to be profitable opportunities that are unexploited.

22 Totals are presented with and without including taxis since these jobs seem to have much larger earnings than other occupations. These average real earnings 
Table 3: Change in Informal Sector Earnings by Declared Occupation Type, 1993 to 1998

\begin{tabular}{|c|c|c|c|c|c|c|c|c|}
\hline \multirow[t]{2}{*}{ Occupation } & \multicolumn{3}{|l|}{1993} & \multicolumn{3}{|l|}{1998} & \multirow{2}{*}{$\begin{array}{l}\text { Percentage } \\
\text { increase } \\
\text { (mean) }\end{array}$} & \multirow{2}{*}{$\begin{array}{l}\text { Percentage } \\
\text { increase } \\
\text { (median) }\end{array}$} \\
\hline & Frequency & $\begin{array}{l}\text { Mean } \\
\text { earnings } \\
(\mathrm{SE})\end{array}$ & $\begin{array}{l}\text { Median } \\
\text { earnings }\end{array}$ & Frequency & $\begin{array}{l}\text { Mean } \\
\text { earnings } \\
(\mathrm{SE})\end{array}$ & $\begin{array}{l}\text { Median } \\
\text { earnings }\end{array}$ & & \\
\hline Shopkeeper & 13 & $235(70)$ & 165 & 9 & $856(395)$ & 426 & $264 \%$ & $158 \%$ \\
\hline Street vendor & 16 & $278(103)$ & 92 & 25 & $295(105)$ & 128 & $6 \%$ & $39 \%$ \\
\hline Shebeen operator & 12 & $140(29)$ & 114 & 21 & $315(81)$ & 213 & $125 \%$ & $87 \%$ \\
\hline Sew/sell clothes & 16 & $220(46)$ & 200 & 11 & $314(200)$ & 142 & $43 \%$ & $-29 \%$ \\
\hline Taxi & 5 & $2,430(1,053)$ & 1550 & 6 & $4,020(1,505)$ & 2,411 & $65 \%$ & $56 \%$ \\
\hline Construction & 8 & $491(194)$ & 300 & 9 & $303(116)$ & 355 & $-38 \%$ & $18 \%$ \\
\hline Other self-employment & 37 & $112(25)$ & 54 & 20 & $399(180)$ & 134 & $256 \%$ & $148 \%$ \\
\hline Casual labourer & 42 & $230(31)$ & 200 & 63 & $388(35)$ & 297 & $69 \%$ & $49 \%$ \\
\hline Other casual work & 23 & $249(53)$ & 200 & 48 & $558(66)$ & 482 & $124 \%$ & $141 \%$ \\
\hline Total & 172 & $281(44)$ & 158 & 212 & $525(67)$ & 297 & $87 \%$ & $88 \%$ \\
\hline $\begin{array}{l}\text { Total excluding taxi } \\
\text { operators }\end{array}$ & 167 & $217(20)$ & 140 & 206 & $423(37)$ & 284 & $95 \%$ & $103 \%$ \\
\hline
\end{tabular}

Source: KwaZulu-Natal Income Dynamics Study (KIDS). 
and median wages for 1993 and 1998, as well as the percentage increase by occupational type. Excluding the earnings changes for street vendors, those sewing and selling clothes, and construction workers, the percentage gains in mean and medians for each occupational category have been $49 \%$ or greater. ${ }^{23}$

In summary, we started this section by using our panel data to show that the change in the labour market for Africans in KwaZuluNatal has been quite progressive in nature. Those starting in the best employment positions (formal workers and workers earning more than twice the low earnings line) experienced earnings losses on average. Those starting in the informal sector experienced sizeable gains on average. The unemployed, of course, averaged positive earnings gains, the magnitude of which was surprisingly large.

These progressive changes occur even though cross-sectional earnings inequality has increased. Moreover, we have shown that this progress did not accord with the picture that emerged from an analysis of the formal sector cross-section data. This cross-sectional perspective seemed to imply that the pattern of earnings dynamics was regressive in KwaZulu-Natal. The cross-sectional analysis of the informal sector gave more support to the progressivity of earnings. The results show that cross-sectional data cannot provide answers to the kinds of fundamentally dynamic questions that policy makers have in mind when assessing the costs and benefits of labour market changes to workers at different positions in the earnings distribution. This is particularly important because many of the key labour market questions in contemporary South Africa are dynamic rather than static, and our results establish clearly that the earnings changes were larger for workers with the lowest initial reported earnings and those who started employed informally or were not employed at all.

Keeping these issues in mind, for the rest of the paper we focus exclusively on the longitudinal nature of the panel in order to

results are considerably lower (2,180 rather than 2,430 in 1993 and 3,945 rather than 4,020 in 1998) when a $5 \%$ annual return to capital stock is removed from self-employment income.

${ }^{23}$ It is interesting to note that a considerable amount of research has focused on street traders. (See, e.g., work by Francie Lund and Caroline Skinner in School of Development Studies, University of Natal Durban, Working Papers 15, 18, 19, 34 and 49.) Our data suggest this group may be experiencing changes that are out of step with that of much of the informal economy, but, again, small sample sizes do not allow a clear statement to this effect. 
investigate factors that appear related to earnings changes in KwaZulu-Natal.

\section{Further Analysis of the Determinants of Earnings Changes}

In the previous sections, we provided evidence that prime working aged Africans enjoyed large earnings gains on average and that these gains were progressive in terms of initial earnings levels and in the base-year sector of employment. This naturally leads one to ask, how did this happen? The rest of the study provides a first step in addressing this question. We provide an extensive description of how earnings changes relate to the most obvious sources: a change into or out of employment or across informal and formal sectors. We also assess how other important base year covariates-those based on demographics and initial employment outcomes-relate to earnings changes. We then combine employment status changes and the other base year covariates into a multivariate analysis of earnings changes. We explore both the direction of earnings change associated with these characteristics and the importance of these characteristics in the ability to account for the variation in earnings changes.

\subsection{Work Status Transitions and Their Relation to Earnings Change}

First, we explore the ways in which employment dynamics relate to the change in earnings that African workers experienced. Table 4 is a work status transition matrix. ${ }^{24}$ The first row includes only those who were formal workers in 1993. Reading across, 58\% were again engaged in formal employment in 1998, 18\% had moved to the informal sector and $24 \%$ were no longer employed. The second and third rows provide similar details for those initially in the informal sector and those initially not employed, respectively. Table 4 shows that many people have moved into and out of employment, and many others have moved between the formal and informal sectors of the economy.

24 There are 915 panel individuals with reported employment status in both periods. Thirty-two of these observations do not have earnings change information (split approximately evenly between missing 1993 earnings and missing 1998 earnings). Therefore, all analysis regarding earnings changes is conducted on the sub-sample of 883 individuals with reported earnings. 
Table 4: Work Status Transition Matrix, Number and Percent in 1998 (Work Status Conditional on 1993 Work Status)

Formal sector in 1998 Informal sector in 1998 Not employed in 1998 Total (\% of column total)

\begin{tabular}{|c|c|c|c|c|}
\hline \multirow[t]{2}{*}{ Formal sector in 1993} & 191 & 59 & 77 & 327 \\
\hline & $58 \%$ & $18 \%$ & $24 \%$ & $36 \%$ \\
\hline \multirow[t]{2}{*}{ Informal sector in 1993} & 30 & 72 & 70 & 172 \\
\hline & $17 \%$ & $42 \%$ & $41 \%$ & $19 \%$ \\
\hline \multirow[t]{2}{*}{ Not employed in 1993} & 81 & 85 & 249 & 415 \\
\hline & $19 \%$ & $21 \%$ & $60 \%$ & $45 \%$ \\
\hline
\end{tabular}

Source: KwaZulu-Natal Income Dynamics Study (KIDS). 
Given that the data set is limited to only two points in time, there is no way to identify spells of employment or unemployment that may have occurred in the intervening years. It is clear, however, that all workers are vulnerable to future spells of non-employment. For example, nearly one in four of those employed in the formal sector in 1993 were not working in 1998. For those formal workers who were in unions in 1993, 21\% were not working in 1998 (results not shown). Even among those earning greater than twice the low earnings line in 1993, 19\% were not working in 1998 (results not shown).

Table 5 provides a first look at how these movements across sectors of employment and into and out of employment relate to changes in earnings. The table provides the average and median earnings change by particular work status transition experience. The median figures are reported as a check on the means. As the median figures reflect a similar situation to the means, only the means will be discussed. For example, the average earnings change for those who were in formal employment in 1993 and were not employed in 1998 was a loss of R818. The loss for those who moved from informal employment to non-employment was R182.

These average earnings changes provide some useful insights and also some surprising information. First, as expected, the gains associated with entering the formal sector are larger than the gains associated with entering the informal sector. Likewise, the losses associated with leaving the formal sector are greater than the losses associated with leaving the informal sector. The fact that the average gains from entering are larger than the average losses from leaving is to be expected given the cross-sectional differential in average earnings for each sector. However, these declines were less than the average 1993 earnings in each sector, implying that the individuals losing their jobs were below average in earnings potential for their respective sectors.

Secondly, the earnings changes for those who are employed in the same sector in both periods are positive. Surprisingly, those who remained in the informal sector experienced considerably larger earnings changes on average than those who remained in the formal sector. This average gain of R343 for dual informal workers is particularly strong, given that the average informal worker in 1993 earned R281. This is another sign that some informal workers are engaged in business that has moved well beyond the subsistence 
Table 5: Mean Earnings Change by 1993 and 1998 Work Status(Standard Error) [Medians]

\begin{tabular}{|c|c|c|c|}
\hline & Formal sector in 1998 & Informal sector in 1998 & Not employed in 1998 \\
\hline Formal sector in 1993 & $\begin{array}{l}\text { R207 (83) } \\
\text { [R90] }\end{array}$ & $\begin{array}{l}-\mathrm{R} 145(96) \\
{[-\mathrm{R} 80]}\end{array}$ & $\begin{array}{l}-\mathrm{R} 818(111) \\
{[-\mathrm{R} 611]}\end{array}$ \\
\hline Informal sector in 1993 & $\begin{array}{l}\text { R839 (169) } \\
\text { [R383] }\end{array}$ & $\begin{array}{l}\text { R343 (182) } \\
\text { [R132] }\end{array}$ & $\begin{array}{l}-\mathrm{R} 182(29) \\
{[-\mathrm{R} 105]}\end{array}$ \\
\hline
\end{tabular}

Source: KwaZulu-Natal Income Dynamics Study (KIDS). 
level that people often associate with such small businesses or casual employment. On the other hand, the finding that $41 \%$ of those initially in the informal sector end up as zero earners (see Table 4) highlights the casual and risky nature of much informal work.

Thirdly, the earnings changes associated with movements between formal and informal sectors do not appear to be symmetric in nature. When moving from informal to formal employment, earnings increase by a mammoth R839 on average, but the average decrease in earnings from moving to the informal sector from the formal sector is just R145. Table 6 further emphasises this point, presenting the percentage of individuals in a given work experience category who have positive earnings gains between 1993 and 1998 . The movement from informal to formal is again a very positive experience, with fully $87 \%$ of such workers experiencing earnings gains. Most (56\%) of the individuals that move from formal to informal employment experience earnings losses. However, the fact that as many as $44 \%$ of such individuals experience an increase in earnings following such a transition is contrary to the popular belief that such a change implies an automatic loss in earnings. It is, however, consistent with a phenomenon discussed in the literature on the informal sector, where workers gain access to financial or human capital in the formal sector that they later use to create their own businesses (Fields, 1990; Maloney, 1998).

Fourthly, while moving into the formal sector implies nearly universal gains with sizeable average gains, there are other means of improving earnings. In Table 7, we divide the block of workers experiencing positive earnings changes into percentages based upon their work status transition experiences. Table 7 shows that

Table 6: Percentage Experiencing Positive Gains in Real Monthly Earnings by Work Status Transition Experience

Formal sector in 1998 Informal sector in 1998

Formal sector in 1993

63

44

Informal sector in 1993

87

67

Source: KwaZulu-Natal Income Dynamics Study (KIDS). 
Formal sector in 1993 Informal sector in 1993 Not employed in 1993 Total
31.4

7.3

19.9

58.7
6.7

13.5

21.1

41.3

Source: KwaZulu-Natal Income Dynamics Study (KIDS).

$41 \%$ of the people who had positive earnings gains were working in the informal sector in 1998, including a contingent of workers who were previously working in the formal sector. An additional $31 \%$ of positive gainers were in the formal sector in both periods, rather than having changes associated with a transition to the sector. We have already shown that those remaining in the informal sector have large average gains (over R300), ruling out any notions that the formal sector was the only sector providing earnings changes large enough to change a household's level of well-being.

Tables 3-7 provide convincing evidence against the hypothesis that the only way to improve earnings in South Africa is by acquiring a formal sector job. The distribution of earnings gains breaks down this way: $41 \%$ of individuals who experienced income gains had no involvement with the formal sector in 1998, 31\% of the gainers were formally employed in both periods, and $27 \%$ gained by becoming formally employed. Thus, although formal employment is an important means of upward mobility, upward mobility within the informal sector is also of considerable importance in KwaZulu-Natal.

\subsection{The Relative Importance of Different Variables in Accounting for} Earnings Changes

In order to better understand the role that work status transitions and other covariates play in earnings changes, we move to a multivariate framework. In this way we can see the influence of 
employment transitions in predicting earnings change when controlling for other observable characteristics that are related to such changes. Basic demographic characteristics, such as age and education, could clearly affect one's change in earnings if the returns to experience or to education were changing in the immediate post-apartheid era. Additionally, one's gender and the characteristics of one's initial employment could be linked systematically to earnings changes.

One reason to suspect the change in earnings to differ by education level, in particular, is that multiple studies have noted an increased demand for skilled labour, while often lamenting the lack of skills in the workforce (Lam, 1999; Bhorat, 2000a,b). There are other reasons to suspect that those with different education levels will have different earnings change experiences. For example, steeper age-earnings profiles are commonly associated with the better educated (Ehrenberg and Smith, 2000). Additionally, Schultz suggests that in periods of disequilibrium, the higher educated should adjust more quickly (Schultz, 1975). Although residential restrictions had been removed years earlier, the immediate postapartheid era could certainly be considered a time of disequilibrium as the nation and economy adjusted to the new social order.

Table 8 presents a univariate look at the influence these characteristics have on earnings change. These univariate results are discussed in detail in Cichello et al. (2001a) and we will only summarise them here. Differences amongst demographic characteristics are fewer than expected. Differences across gender are slight and not statistically significant. Differences across education levels are not as large as expected and likewise are not statistically significant. $^{25}$

In general the progressivity of earnings appears to be coming to a large degree within these key demographic groups rather than between them. Although the changes analysed have been relatively similar in terms of Rand increases, the change in terms of percentage gains clearly favour the initially low earning group. Other changes, while not particularly reinforcing the notion of progressive changes in earnings, certainly do not contradict this notion.

Turning now to multivariate analysis, Table 9 presents results from a regression of reported earnings change on work status ${ }^{25}$ However, work presented in Cichello (2002) has shown that these relatively small differentials by education levels could be a by-product of sample attrition. 
Table 8: Average Change in Earnings Among Selected Groups of African Dynamic Labour Force Participants in KwaZulu-Natal, 1993-1998

Percentage of dynamic labour Average force earnings change

Coef. SE

Total

100

$135.9 \quad 35.6$

(A) 1993 demographic characteristics Urban-rural

Rural $\quad 70$

Urban

30

$102.0 \quad 40.8$

KwaZulu-Natal

KwaZulu

85

Natal

15

Gender

Female

59

Male

41

Age

25-34 years old

46

35-44 years old

35

$45-54$ years old

20

Education level

None

14

Some/completed primary

41

Some/completed secondary $\quad 42$

Post-secondary

3

Household head

No

72

Yes

28

Stokvel member in household

No

Yes

94

6

Other formal sector worker

in household

No

Yes

$118.0 \quad 34.3$

$161.7 \quad 67.3$

(continued on next page) 
Percentage of dynamic labour Average

force

earnings change

Coef. SE

(B) 1993 labour market outcomes

Work status

Non-available $\quad 16$

Discouraged 24

Searching 6

Informal employment 20

Formal employment $\quad 35$

(B1) Characteristics of those employed in 1993

Occupational skill level

Unskilled

35

Semi-skilled 35

Skilled 9

Self-employed, skill unknown 22

Industry of employment

Agriculture

13

Commerce 16

Services 40

Manufacturing 25

Other

(B2) Characteristics of 1993

formal employees only

Non-union

66

Union

34

Private employee

76

Public/parastatal employee

$*$

$235.9 \quad 51.7$

$289.4 \quad 52.2$

$371.8 \quad 95.2$

$215.9 \quad 82.6$

$-103.7 \quad 50.0$

$+$

$\begin{array}{ll}-12.6 & 86.3\end{array}$

$-112.1 \quad 63.1$

$\begin{array}{ll}-43.6 & 146.5\end{array}$

$258.3 \quad 124.8$

$-39.8 \quad 37.4$

$202.5 \quad 175.8$

$-4.9 \quad 67.2$

$-57.7 \quad 122.6$

$-145.5 \quad 114.3$

$-160.8 \quad 50.2$

$8.2 \quad 127.3$

$-107.8 \quad 63.1$

$-90.8 \quad 105.4$

Source: KwaZulu-Natal Income Dynamics Study (KIDS). Point estimates and standard errors derived using 1993 sample weights (adjusted for January 2003 re-release) and observations from those resident in both 1993 and 1998.

*Statistically significant at the $5 \%$ level using an F-test on category variables

${ }^{+}$Statistically significant at the $10 \%$ level using an F-test on category variables. 
Number of observations

883

Adjusted R-squared

0.344

Coef.

SE

Constant

466

541

(A) 1993-1998 employment dynamics:

work status transition experience

Formal to formal

Formal to informal

Formal to not employed

Informal to formal

$-420$

160

Informal to informal

$-1,082$

158

197

160

Informal to not employed

$-309$

216

$-885$

137

Not employed to formal

$-119$

264

Not employed to informal

$-1,064$

263

Not employed to not employed

$-1,362$

266

(B) Initial (1993) earnings level

0 earners

1,487

313

$<0.5 \mathrm{LE}$ line (R1 to R280)

1,044

243

0.5-1 LE line (R280-R560)

950

241

1-2 LE line (R560-R1119)

562

206

$>2$ LE line ( $>$ R1119)

(C) 1993 labour market outcomes

(C1) Characteristics of 1993 employees

Occupational skill level

Unskilled

Semi-skilled

$-64$

146

Skilled

148

238

Self-employed, skill unknown

202

126

Industry of employment

Manufacturing

Agriculture

$-300$

121

Commerce

54

Services

$-148$

113

Other

$-220$

124

(C2) Characteristics of 1993

formal employees only

Union member

233

122

Public or parastatal employee

40

126

(continued on next page) 
(D) 1993 demographic characteristics

Urban

122

87

Resident of Natal

$-171$

74

Male

145

63

Age

$-52.5$

23.8

Age squared

0.62

0.33

Education level

None

Some/completed primary

Some secondary or beyond Household head

Stokvel member in household

Source: KwaZulu-Natal Income Dynamics Study (KIDS).

* Statistically significant at the 5\% level using an F-test on category variables.

transition experiences, reported initial earnings category, and base year demographic and labour market covariates.

When interpreting the results, one must take care that the ceteris paribus implications of interpretation are appropriate. The base case is a formal sector employee earning more than twice the low earnings line in 1993 who is again employed in the formal sector in 1998. Thus, when comparing the predicted change to the predicted change of an individual who is not employed in both periods, 'all else equal', one must recognise that this implies a change to zero earner status in the 1993 earnings category. Therefore, the earnings changes for those who start non-employed are greater than the base case; excluding the dual non-employed, they are quite a bit greater.

Work status transitions and initial earnings are clearly important variables in predicting income change. Wald tests strongly reject the null hypothesis that work status transitions and initial income are unrelated to income change, ceteris paribus. Additionally, the coefficients for different initial earnings experiences and work status transitions are extremely large in magnitude. For example, 
a person who moved from the formal to the informal sector would have a predicted income change R420 less than an otherwise identical person who was again in the formal sector in 1998. Likewise, someone who started just above the low earnings line would have a predicted change R562 higher than an otherwise identical person who earned more than twice the low earnings line in 1993.

Those who had higher initial earnings in 1993, controlling for other base year characteristics, had substantially lower predicted earnings in 1998. As mentioned previously, satisfactory instruments for initial earnings are not available. Therefore, it is not possible to implement a reasonable instrumental variables approach to determine if this result would hold for measures of earnings free of measurement error. Initial earnings may also be capturing correlations due to individual specific idiosyncratic components.

The importance of work status transitions in accounting for change in earnings can be shown by comparing its explanatory power to that of all other covariates. Regressing earnings change on base year covariates including initial income quintile and initial sector of employment (but excluding work status transitions) reduces the adjusted R-squared from 0.344 to 0.127 (not shown). On the other hand, running earnings change solely on work status transition dummies gives an adjusted R-squared of 0.270 (not shown).

Another way to demonstrate the importance of work status is to decompose the sources of inequality in the earnings change distribution. We can answer the question, 'How much of the inequality in the change in earnings is attributable to factors such as initial work status, education, age, etc.?' using the following decomposition (Fields and Yoo, 2000; Fields, 2003). Let $Y_{i}$ denote the $i$ th workers change in earnings. The equation determining $Y$ (the regression corresponding to Table 9) can be written as follows:

$$
Y_{i}=\sum_{j} a_{j} p_{i j}=a^{\prime} P_{i}
$$

where

$$
a=\left[\alpha \beta_{1} \beta_{2} \cdots \beta_{J} 1\right]
$$

and 


$$
P=\left[1 p_{1} p_{2} \cdots p_{J} \varepsilon\right]
$$

Given the earnings mobility function (1), let an inequality index $I(Y)$ be defined on the vector of $Y_{i} \mathrm{~s}: Y \equiv\left(Y_{1}, \ldots, Y_{N}\right)$. Let $s_{j}(Y)$ denote the share of the inequality of $Y$ that is attributable to the $j$ th explanatory factor and let $R^{2}(Y)$ be the fraction of inequality that is explained by all of the Ps taken together. Then, the inequality of $Y$ can be decomposed as

$$
s_{j}(Y)=\frac{\operatorname{cov}\left[a_{j} P_{j}, Y\right]}{\sigma^{2}(Y)}=\frac{a_{j}^{*} \operatorname{cov}\left[P_{j}, Y\right]}{\sigma^{2}(Y)},
$$

where

$$
\begin{aligned}
& \sum_{j=1}^{J+2} s_{j}(Y)=100 \%, \\
& \sum_{j=1}^{J+2} s_{j}(Y)=R^{2}(Y) .
\end{aligned}
$$

The $s_{j} s$, the so-called 'factor inequality weights', hold for any inequality index $I\left(Y_{1}, \ldots, Y_{N}\right)$, which is continuous and symmetric and for which $I(\mu, \mu, \ldots, \mu)=0$. Virtually all inequality indices, such as the Gini coefficient and the Theil index, satisfy these properties.

Table 10 decomposes the sources of inequality in the earnings change distribution using this methodology. Work status transitions account for more than any other category of variables, singlehandedly accounting for $51 \%$ of the predicted portion of earnings change.

Another result in Table 10 is the surprisingly limited importance of demographic characteristics in explaining changes in individual earnings when we also control for work status transitions. Some of these demographic variables had been statistically significant in the multiple regression in Table 9. Interestingly, these demographic variables, after conditioning on the work status transition one experiences and the earnings that one had in 1993, appear to work in favour of those typically associated with initial advantages: urban residents and male workers. Thus, when such initially 
Initial earnings

Demographic characteristics

Urban

Natal

Gender

0.1

Age

Education

Household head

Stokvel

Other formal sector worker in household

1993 Labour Market Outcome

Work status (omitted-part of transitions)

Skill

Industry

Union

Public/Parastatal

Work status transition experience

Total explained

Source: KwaZulu-Natal Income Dynamics Study (KIDS).

advantaged workers do become employed, they appear to break in at higher earnings levels within a sector than rural residents and females do. In comparison with employment changes or unexplained components, however, these changes play a very small role in accounting for earnings changes on the whole. To the extent that work status transitions are based on demographics, endogeneity within the estimated regression could be limiting the apparent role of demographics. Yet, combining this result with the limited importance of demographic variables found in the univariate setting and the much lower ability for demographics and base year outcomes to predict earnings change in a multivariate 
setting, we conclude that such demographic influences are minor at best.

\section{Conclusions}

This paper asked three broad questions and reached the following general answers. First, did African workers get ahead or fall behind in KwaZulu-Natal? Our answers are, first, that average earnings grew substantially. Looking behind the average, more people got ahead than fell behind but $30 \%$ of the labour force were earning less in 1998 than in 1993. Additionally, many people's earnings did not change at all. Looking specifically at a low earnings line, our analysis shows that large numbers of workers escaped poverty but large numbers also fell into poverty.

Our second question was whether the patterns of earnings changes in KZN were progressive or regressive. Using panel data methods, we found that those who started with the lowest earnings and in the poorer employment sectors gained the most. Obviously, workers who started unemployed can only go up, but our results showed that those who started employed in the informal sector enjoyed large earnings gains while those who started formally employed suffered significant earnings losses. We also showed that these sector results would not have been found if cross-sectional methods had been used in place of panel methods. This finding highlights the importance of panel data for answering dynamic labour market questions.

Our third question was how relatively important initial earnings, sector change, demographic factors and other variables were in explaining earnings changes. We found that sector change is the most important variable and initial earnings is a close second. Together, these two variables account for nearly all of the explained variation in earnings changes. The remaining variables-most importantly, the worker's education and gender, but also other demographic and industry variables-explain virtually nothing about earnings change.

Several policy conclusions are suggested by these results. The first is an endorsement of economic growth. Significant numbers of African non-earners and low earners derived notable earnings gains over a period of moderate growth in KwaZulu-Natal. However, our analysis of earnings mobility is not an unconditional endorsement 
of the specific growth path in KwaZulu-Natal. While net earnings were clearly positive there were also many losers in this process. Similarly, we showed that the gain in average earnings occurred in a labour market in which earnings inequality increased between 1993 and 1998.

All of these results for earnings changes among individuals have parallels in prior analysis of household income changes derived from KIDS. Treating the 1993 and 1998 data as two cross-sections, Carter and May (2001), Leibbrandt and Woolard (2001) and Fields et al. $(2003,2004)$ all record increased household inequality in KwaZulu-Natal over the five years. ${ }^{26}$ Carter and May (2001) focus explicitly on poverty and show an increase in measured poverty over the period. Using the panel properties of the data set, these studies go on to analyse social mobility of households. They find strong evidence of income or expenditure mobility. Fields et al. $(2003,2004)$ show that household income changes were positive and progressive on average over the period. As with labour market earnings, they show that there were losers in this broadly positive picture. Carter and May (2001) use expenditure data to show that mobility was stronger for households that were not in the tails of the expenditure distribution and that the current pattern of growth implies a longer run steady state of increased poverty and a substantial number of structurally poor households. Our analysis of the earnings steady state around our low earning line reached a similar conclusion in that the long-run steady state implied an increase in the number of earners falling below the low earnings line. Given both of these findings, there is plenty of support for the emphasis that Carter and May (2001) place on the need to build human capital endowments and other non-human assets as a way of enabling households to avoid or escape poverty and cope with

26 There are a number of important differences in the level of analysis and definition of household well-being across these studies. Carter and May (2001) include both African and Indian households in their analyses, whereas Leibbrandt and Woolard (2001) and Fields et al. (2003, 2004) focus exclusively on African households. Most of these studies make use of household income in measuring household wellbeing and changes to household well-being. However, Carter and May (2001) use household expenditures. While such expenditure data are often thought to have less seasonal variation than income data, the KIDS release uses two different survey methodologies to construct expenditures in the two years. The effect of this change in construction of expenditures has yet to be fully analysed. The measured inequality in this latter study is slightly larger than in the studies that use income. However, the general inequality trend is the same across all of this work. 
labour market shocks and other changes to their environment. More generally, there is plenty of evidence of the need to complement any economic growth policy with micro-interventions focusing on those who are likely losers in this process.

Across all of these studies there is a strong endorsement of all policies promoting an embracing and well-functioning labour market. We conclude with a few suggestions about labour market policy that arise from our analysis in this paper.

There is a need for policies to increase the derived demand for labour in the formal sector. Formal sector employment could be stimulated through two mechanisms:

1. Shifting the demand for labour by promoting growth through increased investment and export expansion. Reliance on maintaining macroeconomic fundamentals has not appeared to be a sufficient condition to induce such investment. The authors believe this to be a necessary condition, but encourage seeking increased input from business executives themselves on how to encourage such investment as well as how to maximise the numbers of jobs per increment of investment.

2. Improving labour market functioning by reducing information and transactions costs associated with the use of labour. These costs include anything from the cost incurred by an unemployed labourer trying to bus into the city to find work to the cost incurred by an employer who is trying to dismiss a completely non-productive worker. Such costs inhibit the formation of potentially vibrant job matches and earnings growth. More analysis is certainly needed to determine the extent to which such costs hinder job creation but the authors believe these costs to be important.

As for policies with respect to the informal sector, we see the need for a more positive and proactive policy towards this sector. The informal sector is not simply a repository of survivalist activities. Rather, it is dynamic and the source of employment and earnings growth for large numbers of KZN workers. Additionally, evidence is suggestive of continued barriers to entry in this sector. These barriers need to be uncovered and assessed.

Looking to the future, the most important task that lies ahead is to understand better the workings of various segments of the South 
African labour market and the interactions between them. The crucial elements that need to be analysed are earnings levels and changes and employment structures and transitions.

Additionally, the sources of dynamism in the informal sector are not well understood. In order to implement policies to raise productivity and earnings within informal wage employment and self-employment, a better understanding of the institutions at work in the informal market is needed. Recent work by Devey et al. (2002) represents a starting point for a serious nationally representative empirical investigation into the workings of the informal sector and the determinants of earnings in this portion of the economy. This investigation should continue and should be considerably extended.

Research into the barriers or 'hidden costs' (i.e., costs that household surveys / economists do not usually adequately consider) within the informal economy is an important next step. Some such barriers or costs are already recognised. Kingdon and Knight (2001b) list capital/land/credit constraints, local licenses and bylaws regulating informal activity, a lack of entrepreneurial knowledge and trade networks given the apartheid past, theft from or violence to self-employed owners and the lack of infrastructure. A qualitative approach may well be necessary to find what other barriers to entry and hidden costs exist within the informal sector, how the factors listed above impact informal employees and how they may be overcome. Such qualitative studies should be followed up with more extensive quantitative analysis to determine the extent to which such problems are hindering growth on a larger scale.

Much can be learned from analysis of panel data that cannot be learned otherwise. There is a panel component to the twice-yearly Labour Force Surveys that Statistics South Africa has been conducting since 2000. There have been a few delays in the release of this panel in usable form. It is important that analysis begin as soon as possible. This will allow for a national picture to be drawn. In addition, another important task is to take advantage of the third round of data from the KZN panel that served as the basis for this paper. The third round, in the field in early 2004, will provide useful information for both analytical and policy purposes. 
Allanson, P., J. Atkins and T. Hinks (2002) 'No End to the Racial Wage Hierarchy in South Africa?', Review of Development Economics, 6 (3): 442-59.

Bhorat, H. (2000a) 'The Impact of Trade and Structural Changes of Sectoral Employment in South Africa', Development Southern Africa, 17 (3): 437-66.

Bhorat, H (2000b) 'Wage Premia and Wage Differentials in the South African Labour Market', paper presented at Trade and Industry Policy Secretariat 2000 Annual Forum, Muldersdrift, 18-20 September.

Bhorat, H. and J. Hodge (1999) 'Decomposing Shifts of Labour Demand in South Africa', South African Journal of Economics, 67 (3): $348-80$.

Bhorat, H. and M. Leibbrandt (2001) 'Correlates of Vulnerability in the South African Labour Market', in H. Bhorat, M. Leibbrandt, M. Maziya, S. Van der Berg and I. Woolard (eds), Fighting Poverty: Labour Markets and Inequality in South Africa, Cape Town: UCT Press.

Carter, M. and J. May (1998) 'Poverty, Livelihood and Class in Rural South Africa', World Development, 27 (1): 1-20.

Carter, M. and J. May (2001) 'One Kind of Freedom: Poverty Dynamics in Post-apartheid South Africa', World Development, 29 (12): 1987-2006.

Carter, M., L. Haddad, J. May and J. Maluccio (2003) 'KwaZuluNatal Income Dynamics Study (KIDS) 1993-1998, Overview and Description of Data Files, Version 3', Washington DC: International Food Policy Research Institute.

Cichello, P (2002) ‘ncome and Earnings Dynamics Among Africans in Post-Apartheid KwaZulu-Natal' Ph.d. Dissertation. Cornell University. UMI Dissertation Services: Ann Arbor, MI.

Cichello, P., G. Fields and M. Leibbrandt (2001a) 'Are African Workers Getting Ahead in the New South Africa? Evidence from KwaZulu-Natal, 1993-98', Social Dynamics, 27 (1): 120-39.

Cichello, P., G. Fields and M. Leibbrandt (2001b) 'Which African Workers Have Gotten Ahead and by How Much? The Story of KwaZulu-Natal, South Africa, 1993-98', Final Report to the South African Department of Finance, March. 
Cichello, P., G. Fields and M. Leibbrandt (2003) 'Earnings and Employment Dynamics for Africans in Post-apartheid South Africa: A Panel Study of KwaZulu-Natal', Working Paper No. 03/77, Development Policy Research Unit (DPRU), School of Economics, University of Cape Town, May.

Devey, R., C. Skinner and I. Valodia (2002) 'The Informal Economy in South Africa: Who, Where, What and How Much?' presented at the DPRU Labour Markets and Poverty in South Africa Conference, Johannesburg.

Dinkelman, T (2002) 'Investigating the Impact of Households on Search Choice and Outcomes in the Kwazulu-Natal Labour Market 1993-1998', unpublished Master's dissertation, Economics Department, University of the Witwatersrand.

Edwards, L. (2000) 'Labour Shedding Output Growth: Is Trade the Culprit?', Trade and Industry Monitor, 14: 2-5.

Ehrenberg, R. and R. Smith (2000) Modern Labour Economics, 7th edn, Reading MA: Addison-Wesley.

Fallon, P. and R. Lucas (1998) 'South African Labour Markets: Adjustment and Inequalities', Washington DC: World Bank Southern African Department, Discussion Paper No. 12, Informal Discussion Papers on Aspects of the Economy of South African.

Fedderke, J. and M. Mariotti (2002) 'Changing Labour Market Conditions in South Africa: A Sectoral Analysis of the Period 1970-1997', South African Journal of Economics, 70 (5): 833-65.

Fields, G.S. (1990) 'Labour Market Modelling and the Urban Informal Sector: Theory and Evidence', in D. Turnham, B. Salome and A. Schwarz (eds), The Informal Sector Revisited, Paris: Organisation for Economic Cooperation and Development.

Fields, G.S. (2003) 'Accounting for Income Inequality and Its Change: A New Method, with Application to the Distribution of Earnings in the United States', in S. Polachek (ed), Research in Labour Economics, Volume 22: Worker Well-Being and Public Policy, Orlando: Elsevier Publishing.

Fields, G.S. and G. Yoo (2000) 'Falling Labour Income Inequality in Korea's Economic Growth: Patterns and Underlying Causes', Review of Income and Wealth, 46 (2): 139-60. 
Fields, G.S., M. Leibbrandt and J. Wakeford (2000) 'Key Labour Market Elasticities', unpublished report to the South African Department of Finance.

Fields, G.S., P. Cichello, S. Freije, M. Menendez and D. Newhouse (2003a) 'For Richer or For Poorer? Evidence from Indonesia, South Africa, Spain, and Venezuela', Journal of Economic Inequality, 1 (1): 67-99.

Fields, G.S., P. Cichello, S. Freije, M. Menendez and D. Newhouse (2003b) 'Household Income Dynamics: A Four Country Story', Journal of Development Studies, 40 (2): 30-54.

Hofmeyr, C. (2000) 'The Changing Pattern of Segmentation in the South African Labour Market', Studies in Economics and Econometrics, 24 (3): 109-28.

Hofmeyr, J. and R. Lucas (2001) Labour, 15 (4): 685-719.

Jensen, R (1999) 'A Semi-Parametric Analysis of African-White Wages Differences in the South African Public and Private Sectors', mimeo, John F. Kennedy School of Government, Harvard University.

Keswell, M (2000) 'Labour Market Dynamics in South AfricaEvidence from KwaZulu-Natal Province', paper presented at the Trade and Industry Policy Secretariat 2000 Annual Forum, 18-20 September, Muldersdrift.

Keswell, M (2002) 'Mobility and the Evolution of Inequality in South Africa', unpublished paper, School of Economics, University of Cape Town.

Kingdon, G. and J. Knight (2000a) 'Are Searching and Nonsearching Unemployment Distinct States when Unemployment is High? The Case of South Africa', Centre for the Study of African Economies Working Paper, University of Oxford.

Kingdon, G. and J. Knight (2000b) 'The Incidence of Unemployment in South Africa', paper presented at the Trade and Industry Policy Secretariat (TIPS) 2000 Annual Forum, 18-20 September, Muldersdrift.

Kingdon, G. and J. Knight (2001a) 'What Have We Learnt about Unemployment from Microdatasets in South Africa?', Social Dynamics, 27 (1): 79-95.

Kingdon, G. and J. Knight (2001b) ‘Why High Open Unemployment and Small Informal Sector in South Africa?' paper presented at 
the Labour Markets and Poverty in South Africa Conference, 2001, 15-16 November, Johannesburg.

Klasen, S. and I. Woolard (1999) 'Levels, Trends and Consistency of Employment and Unemployment Figures in South Africa', Development Southern Africa, 16 (1): 3-35.

Lam, D (1999) 'Generating Extreme Inequality: Schooling, Earnings, and Intergenerational Transmission of Human Capital in South Africa and Brazil'. Population Studies Center Research Report, Institute for Social Research, University of Michigan, 99-439, August.

Leibbrandt, M. and I. Woolard (2001) 'The Labour Market and Household Inequality in South Africa: Existing Evidence and New Panel Data', Journal of International Development, 13 (6): 671-89.

Maloney, W.F (1998) 'Are Labour Markets Dualistic?' Working Paper No. 1941, Washington DC: World Bank, February.

Maluccio, J., L. Haddad and J. May (2000) 'Social Capital and Income Generation in South Africa 1993-1998', Journal of Development Studies, 36 (6): 54-81.

May, J., M. Carter, L. Haddad and J. Maluccio (2000) KwaZulu-Natal Income Dynamics Study (KIDS) 1993-98: A Longitudinal Household Data Set for South African Policy Analysis, University of NatalDurban, University of Wisconsin-Madison and International Food Policy Research Institute.

Michaud, P. and D. Vencatachellum (2001) 'Female and Male Union Wage Premium in South Africa', unpublished seminar paper, School of Economics, University of Cape Town, August.

Moll, P. (1993) 'Industry Wage Differentials and Efficiency Wages', Journal of Development Economics, 41 (2): 213-46.

Moll, P. (2000) 'Discrimination is Declining in South Africa but

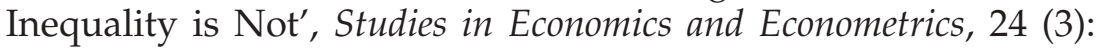
91-108.

Muller, C (2003) 'Measuring South Africa's Informal Sector: An Analysis of National Household Surveys', Working Paper No. 03/71, DPRU, School of Economics, University of Cape Town.

Mwabu, G. and T.P. Schultz (1996) 'Education Returns Across Quantiles of the Wage Function; Alternative Explanations for 
the Returns to Education by Race in South Africa', American Economic Review, 86 (2): 335-9.

Mwabu, G. and T.P. Schultz (1998) 'Labour Unions and the Distribution of Wages and Employment in South Africa', Industrial and Labour Relations Review, 51 (4): 680-703.

Mwabu, G. and T.P. Schultz (2000) 'Wage Premiums for Education and Location of South African Workers, by Gender and Race', Economic Development and Cultural Change, 48 (2): 307-34.

Nattrass, N. (2000a) 'Inequality, Unemployment and Wage-Setting Institutions in South Africa', Studies in Economics and Econometrics, 24 (3): 129-42.

Nattrass, N. (2000b) 'The Debate About Unemployment in the 1990s', Studies in Economics and Econometrics, 24 (3): 73-89.

Nelson, R. (1956) 'A Theory of the Low-level Equilibrium Trap in Underdeveloped Economies', American Economic Review, 46 (5): 894-908.

Poswell, L (2002) 'The Post-apartheid South African Labour Market: A Status Report', Development Policy Research Unit, School of Economics, University of Cape Town, February.

Rospabe, S (2001) 'How Did Labour Market Racial Discrimination Evolve After the End of Apartheid', unpublished seminar paper, School of Economics, University of Cape Town, November.

Schultz, T.W. (1975) 'The Value of the Ability to Deal with Disequilibria', Journal of Economic Literature, 13 (3): 827-46.

Statistics South Africa (2002) 'Earning and Spending in South Africa: Selected Findings and Comparisons from the Income and Expenditure Surveys of October 1995 and October 2000', Pretoria: Statistics South Africa.

Whiteford, A. and D.E. Van Seventer (2000) 'South Africa's Changing Income Distribution in the 1990s', Studies in Economics and Econometrics, 24 (3): 7-30. 
